\section{RMD Open}

Rheumatic \&

Musculoskeletal Diseases

\title{
Incidence of facial nerve palsies stratified by DMARD treatment in patients with rheumatoid arthritis: data from the RABBIT register
}

Yvette Meissner (1D, ${ }^{1}$ Martin Schäfer (D), ${ }^{1}$ Matthias Schneider, ${ }^{2}$ Elke Wilden, ${ }^{3}$ Silke Zinke, ${ }^{4}$ Angela Zink, ${ }^{1}$ Anja Strangfeld ${ }^{1}$

To cite: Meissner $Y$, Schäfer M, Schneider M, et al. Incidence of facial nerve palsies stratified by DMARD treatment in patients with rheumatoid arthritis: data from the RABBIT register. RMD Open 2020;6:e001403. doi:10.1136/rmdopen-2020001403

- Supplemental material is published online only. To view please visit the journal online (http://dx.doi.org/10.1136/rmdo pen-2020-001403).

Received 3 August 2020 Revised 30 September 2020 Accepted 2 October 2020
Check for updates

(c) Author(s) (or their employer(s)) 2020. Re-use permitted under CC BY-NC. No commercial re-use. See rights and permissions. Published by BMJ.

${ }^{1}$ Epidemiology Unit, German Rheumatism Research Centre, Berlin, Germany

${ }^{2}$ Rheumatology, Heinrich-Heine University Düsseldorf, Düsseldorf, Germany

${ }^{3}$ Rheumapraxis, Köln, Germany ${ }^{4}$ Rheuma Praxis Berlin, Berlin, Germany

Correspondence to

Yvette Meissner;

y.meissner@drfz.de

\section{INTRODUCTION}

Spontaneous reports of facial paralysis in patients receiving tocilizumab prompted the Pharmacovigilance Risk Assessment Committee of the European Medicine Agency to investigate this safety signal. ${ }^{1} \mathrm{~A}$ total of 6 facial pareses and 10 facial paralyses have been registered by healthcare professionals (1 paralyses was reported by a non-healthcare professional) in the EudraVigilance database, the spontaneous pharmacovigilance reporting system across the European Union, until 21 March 2020 (http://www.adrreports.eu).

Facial nerve palsies (FNPs) are very rare events. About three quarters are of idiopathic origin and one quarter have a detectable cause and may be related to, for example, surgery, infections, stroke or selected malignancies like pons tumour. ${ }^{2}$ Reported annual incidences of idiopathic FNPs vary widely and range from 11 to 40,20 to 25 or 12 to 53 events per 100000 persons depending on the population investigated. ${ }^{2-4}$ Recently, a UK study based on data of general practices reported an overall incidence of $37.7 / 100000$ person-years. ${ }^{5}$ No data are available on the incidence in patients with rheumatoid arthritis (RA) or on the risk of FNP regarding treatment with diseasemodifying anti-rheumatic drugs (DMARDs).

The aim of this analysis was to investigate whether a safety signal for the interleukin 6-inhibitor tocilizumab is also found in a large observational cohort with known denominators for various treatments. We therefore compared the incidence of FNP in patients with RA receiving tocilizumab to other conventional synthetic (cs), biological (b) or targeted synthetic (ts)DMARDs.

\section{METHODS}

The German register Rheumatoid Arthritis Observation of Biologic Therapy (RABBIT)

\section{Key messages}

What is already known about this subject?

- A safety signal regarding the occurrence of facial paralysis in patients receiving tocilizumab has been reported to the Pharmacovigilance Committee of the European Medicine Agency. ${ }^{1}$

- Facial nerve palsies are rare events, and no information is available on the incidence in patients with rheumatoid arthritis or if DMARD treatment is associated with their occurrence.

What does this study add?

- The incidence rate of facial nerve palsies under tocilizumab was comparable to other biological treatments and higher compared to csDMARDs.

- Patients with facial nerve palsy presented with a more severe course of the rheumatic disease, lower physical function and more comorbidities than patients without facial nerve palsy.

How might this impact on clinical practice?

- It is reassuring to physicians and patients that treatment with tocilizumab was not associated with an increased rate of facial nerve palsy compared to patients receiving other bDMARDs.

is a prospective longitudinally followed cohort of patients with RA who are included with a new start of a b/tsDMARD or a csDMARD after at least one csDMARD failure. ${ }^{6}$ After enrolment, at predefined intervals during follow-up (after 3 and 6 months and every 6 months thereafter), rheumatologists and patients report information on various aspects of their disease including clinical status, actual DMARD treatment and treatment changes (including reasons) since the last report. All adverse events since the last documentation are reported as free text and coded using the Medical Dictionary for Regulatory Activities 
(MedDRA) by the RABBIT team. For this analysis, patients enrolled between January 2007 and April 2020 were selected. All reports of the first FNP (MedDRA terms: facial pareses and facial paralyses) during followup were analysed as outcomes. Patients with a cerebral event known as a possible cause of central FNPs that occurred within the 2 weeks prior to the FNP were excluded from this analysis.

We compared baseline characteristics of patients with FNP during follow-up to those without descriptively. Incidence rates (IR) per 1000 patient-years (PY) were calculated for every treatment. An event was assigned to a b/tsDMARD therapy if the patient had received at least one dose of this medication within a 3-month risk window prior to the event. For rituximab, a 9-month risk window was applied. In case of an exposure to more than one b/tsDMARD, the event was counted for each treatment received within the defined risk window. If no b/tsDMARD was applied within this time frame, the event was assigned to the csDMARD exposure group (controls). Confidence intervals (CIs) for IR were calculated by assuming a Poisson distribution for the observed cases. ${ }^{7}$

In a sensitivity analysis, we excluded patients with a potentially related comorbidity (eg, Sjögren's syndrome) or in whom the FNP was preceded by a potentially related event (eg, infection) with a maximum interval of 2 weeks.

\section{RESULTS}

Between 2007 and 2020, a total of 10 facial pareses and 12 facial paralyses were observed in 14185 patients with RA of the RABBIT cohort. Of those, 3 patients- 1 with facial paresis and 2 with facial paralyses-were excluded because of clearly related causal events (stroke and encephalitis) prior to FNP leaving 19 FNPs for the analysis. The online supplemental table lists all FNPs, prior events and treatment exposures.

The median time from inclusion to FNP was 28 months with a minimum of 1 month and a maximum of 101 months. Four of the events were observed under tocilizumab, leading to an IR of 0.50 per 1000 PY (95\% CI 0.14 to 1.09), which was higher than the IR in patients receiving csDMARDs (0.17 (0.03 to 0.40) ) but was lower than the IRs for other bDMARDs (ranging from 0.61 to 0.76 ) or for baricitinib, a Janus kinase inhibitor, ( $\mathrm{IR}=0.84$ ) (see figure 1A). The observed differences were statistically nonsignificant (based on overlapping CIs). The overall IR of idiopathic FNP among patients with RA receiving DMARDs of any kind was 0.32 (0.20 to 0.49 ).

At the time of inclusion into the cohort, patients with FNPs during follow-up had longer disease duration, were more often autoantibody positive, presented more frequently with joint erosions and had more prior bDMARD treatments before enrolment compared to patients without these events (table 1). Furthermore, patients with FNP had more often prevalent comorbidities (mean of
4.2 vs 2.3 in the remaining cohort). Details on selected comorbidities of patients with FNP are given in the online supplemental table.

In 10 of the 19 patients, other events were reported within a 2-week period prior to the FNP onset. Four of them have had infectious diseases (bacterial bronchitis, mastoiditis, streptococcal infection, tonsillitis).

In a sensitivity analysis, patients with prior infections $(\mathrm{n}=4)$, dental treatment $(\mathrm{n}=2)$ or relevant comorbidities ( $\mathrm{n}=1$ Sjögren's syndrome) were excluded. Consequently, the total IR dropped to $0.20 / 1000$ PY (95\% CI 0.11 to 0.34 ) (figure 1B). Characteristics of patients included in the sensitivity analysis are given in table 1 .

\section{DISCUSSION}

The overall incidence of FNPs among patients with RA receiving DMARDs in the RABBIT register is comparable to the reported incidence in the general population. ${ }^{5}$ To our knowledge, no literature exists describing the incidence of FNPs in patients with RA or under certain DMARD therapies, especially not for tocilizumab. Two case reports describe the development of FNPs in patients with Crohn's disease receiving adalimumab. ${ }^{8} 9$ An increased incidence for patients treated with tocilizumab compared to other b or tsDMARDs cannot be confirmed with our data. However, the incidence of FNPs was higher under bDMARDs compared to csDMARDs.

The aetiology of idiopathic FNP is yet not fully understood; major theories encompass anatomical causes, viral infection, ischaemia, inflammation and cold temperature stimulation. ${ }^{4}$ In a sensitivity analysis, we excluded possibly related risk factors for FNP, which resulted in lower IRs for most of the investigated treatments. Morales et al showed no differences for the occurrence of FNP in men and women. ${ }^{5}$ However, higher incidences were described with increasing age and diabetes, and pregnancy was revealed as a risk factor. ${ }^{5} 1011$ With only 19 reported events in more than 58000 PY, a comprehensive adjustment for risk factors in a regression model would imply an overfitting of the data and, thus, be unlikely to give results reproducible in an independent data set.

The small number of cases with FNP is a limiting factor in analysing and interpreting our results. However, since data are reported to the RABBIT register at regular, fixed time points and closely monitored, events found for patients receiving tocilizumab can be put into context with other RA treatment regimens and also with other events that have occurred prior to the FNP. A comparison of our results to the events reported to EudraVigilance is not possible. Spontaneous reporting systems rely on individual case reports. A reporting bias can therefore not be ruled out. It is likely that events that are suspected to be caused by a specific exposure are more frequently 

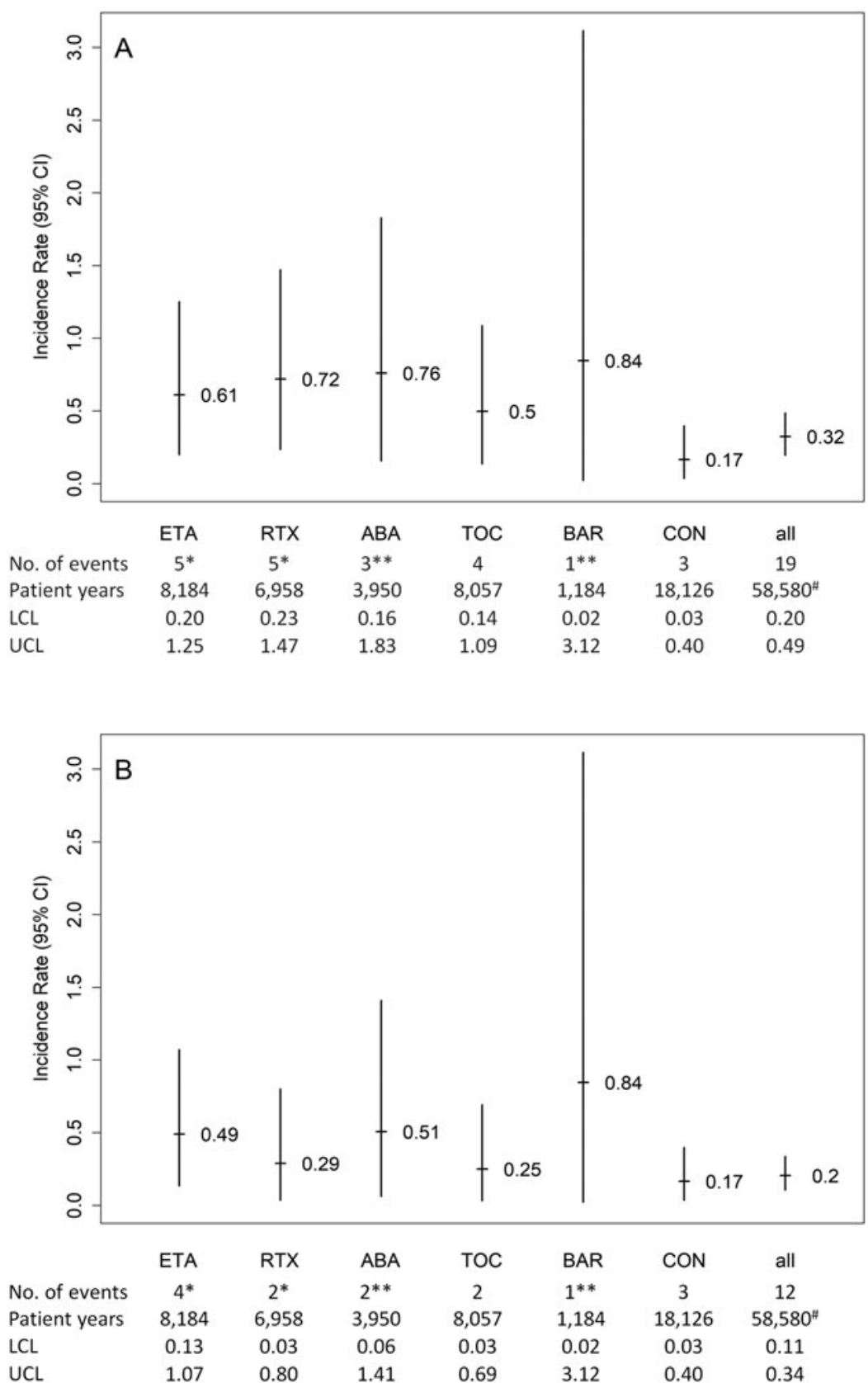

Figure 1 Unadjusted incidence rates per 1000 patient-years $(95 \% \mathrm{Cl})$ for facial nerve palsies stratified by treatment in (A) the main analysis and (B) the sensitivity analysis. ${ }^{*}$ One patient was exposed to both ETA and RTX at the time of event. ${ }^{*}$ One patient wasexposed to both $\mathrm{ABA}$ and BAR at the time of event. \#Encompasses all patients observed inthe RABBIT cohort, including the following therapies without events: adalimumab, certolizumab pegol,golimumab, infliximab, sarilumab, tofacitinib. ABA, abatacept; BAR, baricitinib; CON, csDMARD controls; csDMARD, conventional synthetic disease-modifying anti-rheumatic drug; ETA, etanercept; LCL, lower confidence limit; RTX, rituximab; TOC, tocilizumab; UCL, upper confidence limit.

reported than others. In addition, it is neither known how many patients receive tocilizumab across the European Union nor how complete the reporting is; thus, IRs cannot be calculated. Furthermore, it cannot be distinguished whether events reported to EudraVigilance were idiopathic or caused by other events as the medical history is frequently missing.

\section{CONCLUSION}

This analysis did not find an increased incidence for FNPs in patients treated with tocilizumab compared to other b/tsDMARDs. FNPs are rare events, and the overall IR in patients with RA is comparable to reports from the general population. Whether treatment with specific DMARDs may increase that risk cannot be 
Table 1 Baseline characteristics of patients with facial nerve palsy compared to all patients without the event

Facial nerve palsy during follow-up

Parameter

No facial nerve palsy during follow-up

Main analysis Sensitivity analysis

\begin{tabular}{llll}
\hline No. of patients & 14163 & 19 & 12 \\
\hline Age (years) & $57.7(12.8)$ & $61.4(13.0)$ & $61.6(14.3)$ \\
\hline Women & $10572(74.6 \%)$ & $11(57.9 \%)$ & $9(75.0 \%)$ \\
Disease duration (years) & $9.3(8.8)$ & $11.6(9.8)$ & $9.9(7.0)$ \\
\hline RF or ACPA positive & $10269(73.2 \%)$ & $16(84.2 \%)$ & $9(75.0 \%)$ \\
\hline No. of prior bDMARDs & $0.5(1)$ & $1.3(1.2)$ & $1.4(1.4)$ \\
\hline Joint erosions & $6564(48.8 \%)$ & $11(68.8 \%)$ & $5(55.6 \%)$ \\
DAS28-ESR & $4.8(1.3)$ & $5.0(1.4)$ & $4.6(1.1)$ \\
ESR (mm/hour) & $28.1(22.2)$ & $32.5(23.1)$ & $24.6(14.8)$ \\
CRP (mg/L) & $14.0(20.1)$ & $15.7(15.5)$ & $13.1(16.6)$ \\
\hline \% of full physical function & $65.9(23.2)$ & $57.6(26.2)$ & $57.7(28.3)$ \\
Concomitant glucocorticoid treatment & $10818(76.5 \%)$ & $16(84.2 \%)$ & $9(75.0 \%)$ \\
Actual glucocorticoid dose (mg/day) & $8.8(8.7)$ & $9.5(9.1)$ & $10.2(11.4)$ \\
Ever smoked & $7689(57.3 \%)$ & $10(52.6 \%)$ & $6(50.0 \%)$ \\
\hline Sjögren's syndrome & $170(1.2 \%)$ & $1(5.3 \%)$ & 0 \\
\hline No. of comorbidities & $2.3(2.2)$ & $4.2(3.8)$ & $3.9(4.0)$ \\
\hline
\end{tabular}

ACPA, anti-citrullinated protein antibody; bDMARDs, biological disease-modifying anti-rheumatic drugs; CRP, C reactive protein; DAS28-ESR, the 28-joint disease activity score incorporating erythrocyte sedimentation rate; RF, rheumatoid factor.

concluded from our data since numbers were small and CIs overlapped.

Acknowledgements The authors acknowledge the invaluable contributions of all participating consultant rheumatologists and their patients. In particular, we would like to thank those rheumatologists who enrolled the highest numbers of patients: Kaufmann J, Klopsch T, Braun J, Eisterhues C, Schwarze I, Kneitz C, Möbius C, Ständer E, Rockwitz K, Krause A, Liebhaber A, Zinke S, Kühne C, Berger S, Bohl-Bühler M, Tony $\mathrm{H}$, Worsch $\mathrm{M}$, Harmuth $\mathrm{W}$, Fricke-Wagner $\mathrm{H}$, Feuchtenberger M, Burmester G, Wilden E, Balzer S, Bruckner A, Röser M, Kellner H, Gräßler A, Hamann F, Wiesmüller G, Wassenberg S, Ochs W, Lebender S, Syrbe U, Bergerhausen H, Stille C, Tremel H, Roßbach A, Baumann $\mathrm{C}$, Haas $\mathrm{F}$, Krüger $\mathrm{K}$, Prothmann U, Brandt $\mathrm{H}$, Karberg $\mathrm{K}$, Krummel-Lorenz B, Körber H, Kapelle A, Seifert A, Wernitzsch H, Thiele A, Meier L, Weiß K, Schmitt-Haendle M, Streibl H, Häckel B, Wiesent F, Lorenz H, Blank N, Heel N, Herzer P, Manger K, Dahmen G, Pick D, Feist E, Krause D, Aringer M, Herzberg C, Gause A, Zänker M, Bielecke C, Edelmann E, Reck A, Eidner T, Claußnitzer A, Marycz T, Riechers E, Schulze-Koops H, Müller B, Aurich M, Boldemann R, Alliger $\mathrm{K}$, Mauß-Etzler $\mathrm{U}$, Hauser $\mathrm{M}$, Schibinger $\mathrm{H}$, Fuchs $\mathrm{P}$, Behringer W, Menne H, Mark S, von Hinüber U, Donath G, Häntsch J, Nerenheim A, Schneider M, Erbslöh-Möller B, Detert J, Engel J, Hoese G, Iking-Konert C, Pagel $\mathrm{K}$, Borvendég $\mathrm{T}$, Holst $\mathrm{A}$. We also acknowledge the significant contributions of Peter Herzer, Munich, Jörn Kekow, Vogelsang-Gommern, Bernhard Manger, Erlangen and Matthias Schneider, Düsseldorf, as members of the scientific advisory board.

Contributors YM, MSchäfer, AZ and AS had full access to all data of this study and take responsibility for data integrity and accuracy of the analysis and were responsible for the analysis and interpretation of the data. MSchneider, EW and SZ: acquisition of the data. YM and AS: study concept and design, drafting the manuscript. All authors: critical revision of the manuscript for important intellectual content. All authors read and approved the final manuscript.

Funding RABBIT is supported by a joint, unconditional grant from AbbVie, Amgen, Bristol-Myers Squibb, Celltrion Healthcare, Fresenius Kabi, Hexal AG, Lilly Deutschland, MSD Sharp \& Dohme, Mylan, Pfizer, Roche, Samsung Bioepis, SanofiAventis and UCB. The principal investigators and their team had full academic freedom in study design and conduct, data analysis and publication of results. These stipulations were delineated in their contract with the sponsors. For the purpose of information, all funding companies received the manuscript 30 days prior to submission. Publication of this article was not contingent on their approval. The data interpretation, drafting, critical revision and approval of the final manuscript were performed solely by the authors.
Competing interests YM: lecture honoraria from Pfizer. MSchäfer: none declared. MSchneider: grant/research support from GSK, UCB, Abbvie; consultant of Abbvie, Alexion, Astra Zeneca, BMS, Boehringer Ingelheim, Gilead, Lilly, Sanofi, UCB; speakers bureau: Abbvie, Astra Zeneca, BMS, Chugai, GSK, Lilly, Pfizer, Sanofi. EW: none declared. SZ: none declared. AZ: speakers bureau: AbbVie, Amgen, BMS, Gilead, Hexal, Janssen, Lilly, MSD, Pfizer, Roche, Sanofi Aventis, UCB. AS: speakers bureau: AbbVie, BMS, Pfizer, Roche, Sanofi-Aventis.

Patient consent for publication Not required.

Ethics approval The RABBIT study received approval by the Ethics Committee of Charité-Universitätsmedizin, Berlin, Germany.

Provenance and peer review Not commissioned; externally peer reviewed. Data availability statement Data are not publicly available.

Supplemental material This content has been supplied by the author(s). It has not been vetted by BMJ Publishing Group Limited (BMJ) and may not have been peerreviewed. Any opinions or recommendations discussed are solely those of the author(s) and are not endorsed by BMJ. BMJ disclaims all liability and responsibility arising from any reliance placed on the content. Where the content includes any translated material, BMJ does not warrant the accuracy and reliability of the translations (including but not limited to local regulations, clinical guidelines, terminology, drug names and drug dosages), and is not responsible for any error and/or omissions arising from translation and adaptation or otherwise.

Open access This is an open access article distributed in accordance with the Creative Commons Attribution Non Commercial (CC BY-NC 4.0) license, which permits others to distribute, remix, adapt, build upon this work non-commercially, and license their derivative works on different terms, provided the original work is properly cited, appropriate credit is given, any changes made indicated, and the use is non-commercial. See: http://creativecommons.org/licenses/by-nc/4.0/.

\section{ORCID iDs}

Yvette Meissner http://orcid.org/0000-0003-0147-4112

Martin Schäfer http://orcid.org/0000-0001-6487-3634

\section{REFERENCES}

1 Pharmacovigilance Risk Assessment Committee (PRAC). Minutes of the meeting on 01-04 October 20182018 Available https://www.ema europa.eu/en/documents/minutes/minutes-prac-meeting-1-4-octo ber-2018_en.pdf

2 Finsterer J. Management of peripheral facial nerve palsy. Eur Arch Otorhinolaryngol 2008;265:743-52. 
3 De Diego-Sastre JI, Prim-Espada MP, Fernandez-Garcia F. The epidemiology of Bell's palsy. Rev Neurol 2005;41:287-90.

4 Zhang W, Xu L, Luo T, et al. The etiology of Bell's palsy: a review. $J$ Neurol 2020;267:1896-905.

5 Morales DR, Donnan PT, Daly F, et al. Impact of clinical trial findings on Bell's palsy management in general practice in the UK 2001-2012: interrupted time series regression analysis. BMJ Open 2013;3:e003121.

6 Richter A, Meissner Y, Strangfeld A, et al. Primary and secondary patient data in contrast: the use of observational studies like RABBIT. Clin Exp Rheumatol 2016;34:S79-S86.

7 Ulm K. A simple method to calculate the confidence interval of a standardized mortality ratio (SMR). Am J Epidemiol 1990;131:373-5.
8 Lu LX, Marshall JK. Bell's palsy in a patient receiving adalimumab for Crohn's disease. J Crohns Colitis 2013;7:e115.

9 Yao A, Chan H, Macdonell RAL, et al. Bilateral facial nerve palsies secondary to chronic inflammatory demyelinating polyneuropathy following adalimumab treatment. Clin Neurol Neurosurg 2018;164:64-6.

10 Monini S, Lazzarino Al, lacolucci C, et al. Epidemiology of Bell's palsy in an Italian health district: incidence and case-control study. Acta Otorhinolaryngol Ital 2010;30:198.

11 Rowlands S, Hooper R, Hughes R, et al. The epidemiology and treatment of Bell's palsy in the UK. Eur $J$ Neurol 2002;9:63-7. 